\title{
Unlocking Temporal Leadership to Handle Project Team Performance under Team Conflict
}

\author{
Muhammad Bilal Afzal Kayani
}

Riphah International University, Tecktribe Solutions SMC (Pv) Ltd, Pakistan

\begin{tabular}{l} 
ARTICLE INFO \\
\hline Keywords: \\
Team temporal leadership \\
Task conflict \\
Process conflict \\
Relationship conflict \\
Team performance
\end{tabular}

\section{ARTICLE INFO}

Keywords:

Team temporal leadership

Task conflict

Relationship conflict

Team performance

\begin{abstract}
It is discussed in different studies that the performance of any team is directly or indirectly dependent on the leadership of that team. But there are always some circumstances which affect the performance of a team on various points. These circumstances may include team conflict and its three sub-level conflicts which include task conflicts, relationship conflicts, and process conflicts. The proposed article will be a joint venture of Information Technology and Project Management discipline in which quantitative research method is used. Given the relationship between team temporal leadership and project team performance, it is obligatory for a leader of the technical team to be well aware of managing the conflicts that arise among a team and also be well aware of resources provided by higher-ups. The research will highlight 1) the negative effect of team conflict on the performance of a team, 2) the influence of temporal leadership on team performance and 3) the role of temporal leadership to overcome negative impact of conflicts to improve project team performance.
\end{abstract}

\section{Introduction}

Nowadays the practice followed by companies is that team is formed without checking the team member's behavior and track record which results in a rise of conflicts between team members. The conflicts within the team may be related to tasks distributed among team members, inter-team members relationship-related conflicts, or some time conflict between process implemented on team members to control them and to get work from them. These types of conflicts, directly and indirectly, affect the performance of a team. Especially of a team is of a certain project then, inter-team conflict is a disaster for the project manager because he has to get work as well as to keep his team along with him to make project successful (Maruping, Venkatesh, Thatcher, \& Patel, 2015).

A rapid increase in dependency of the organization on its team to complete a set of tasks is being reported. The US with $82 \%$ of organizations that have employees of 100 or more to some extent rely on teams. Similarly, this figure changes in the European Union where almost $80 \%$ of companies believe that teamwork is a factor that helps an organization to grow in the right direction (Shaw et al., 2011).

\footnotetext{
* Corresponding author E-mail address: thewriters589@gmail.com
} 
In team research usually, two types of teams are observed, one which is a temporary team, mostly change concerning the project, the other one is an ongoing team where project changes from time to time but team members remain the same (Assaf, Hassanain, \& Mughal, 2014). If one compares the working behavior and success ratio of both types of teams, although both have their significant role ongoing teams are considered to be more successful. The reason is to fix team members with strong bonding and understanding who prefer to work for a long period (Ancona, Goodman, Lawrence, \& Tushman, 2001). Conflicts within an organization may occur in both types of team, researchers studied that team conflict may occur in both ongoing and temporary teams but the conflict type may be different and its results may also be different from each other. Similar conflicts in both types of teams may cause different outcomes (Taormina \& Gao, 2013).

A project in any organization is considered as an endeavor that is temporarily but is planned in such a way that specific goals could be achieved with the help of completion of that project. As per the Project Management Institute Book of Knowledge (2013), there are two main dimensions of a project; the first most dimension is that a project should be a temporary entity and the second dimension is, it should achieve certain goals at its completion (Santos, Passos, Uitdewilligen, \& Nübold, 2016).

In the research made by many researchers with time revealed as well as properly described different types of approaches/styles which help leaders to manage things in a proper organized way. These approaches/styles help leaders to organize their subordinates as well as their tasks in such a way that put a positive or sometimes negative impression on their work success (Anderson \& Sun, 2017). Nowadays the researchers are moving towards teamoriented leader styles which helps not only to manage a single task but also helps to manage a team under a leader. Defining team temporal leadership reveals various definitions which are proposed by number of researchers. According to their definitions a general definition of temporal leadership is the behavior of a leader that helps and aid in structuring, coordinating and managing the pacing of task accomplishment in a team to achieve the goals (Mohammed \& Nadkarni, 2011).

In team temporal leadership, a leader only avails those type of behaviour which are taskoriented and are associated with the completion of any task rather than developing relationships with team and adopting relationship-oriented behaviour in style. In another short definition "team temporal leadership involves synchronizing the timing of team member actions so that work is completed on time" (Maruping et al., 2015). Hence this type of leadership style involves scheduling the tasks in such a way that team members have to complete the tasks in a specific time constrain to meet given requirements. This is the way that affects the performance of team members sometimes positively or negatively which depends upon the implementation of style on the team.

This study with the help of supporting theories extends research on temporal leadership by observing and analysing the project team performance and conflicts occur within a team which leads towards project failure. The study describes the effects of team temporal leadership associated with temporal tension, employee performance, role innovation, career commitment, and employee voice behaviour. The current study seeks to predict paths linking team temporal leadership with several related constructs. The purpose of this paper is Unlocking Team Temporal Leadership to Handle Project Team Performance under Team Conflict and Managerial Information Technology Resource. In Information Technology industry work is to be done in the form of projects and teams are allocated for projects to complete them. In such type of industry team conflicts usually occur, so project managers usually have to take care of such conflicts while keeping all types of managerial resources in mind to rectify conflicts so that performance of team remains constant and has not been affected due to any sought of conflict (Santos et al., 2016). 
According to the McGrath's theory of time, interaction and performance (TIP), conflicts within team occurs due to orientations of temporal diversity and this temporal diversity may include work activity scheduling, process implementation within a team, inter-team member bonding which affects the output and deadline of a project (Mohammed \& Nadkarni, 2011). In the information technology industry considering most important part of the project is scheduling of work, making process to implement a project and making SOP's which must have to be followed by team members while working on a project and its implementations are strongly observed. A frequent change in demands of organizations, temporal leadership became important to be adopted by high-level management to maintain the performance level of teams, as $80 \%$ of companies depend on the project which is a time-based activity, such activities required temporal leadership, which have enough flexibility to meld itself according to the working environment (Brannick, Salas \& Prince, 1997).

\subsection{Research Gap}

Researchers proposed a theoretical model that links temporal leadership with the outcomes of a project. In their study, they suggested that an empirical analysis could be performed to test the impact of temporal leadership on project team performance at different levels which may be either at the team level, individual level, or at the organizational level. Almost 6 years have passed and still few research studies are proposed by research on this style of leadership (Taormina and Gao, 2013).

Kearney and Geberth (2009) in their study suggested that researchers must study the impact of temporal leadership on different industries other than industries that are involved in manufacturing. As in the past one found quite low literature on temporal leadership and most of the work was done by keeping manufacturing industries in mind. The main reason behind this choice is a large number of working in manufacturing industries as well as a strong leadership hierarchy. In the account of this, the current study will be focusing the Information Technology industry of Pakistan's 4 cities.

\subsection{Problem Statement}

In performing complex tasks, it doesn't just include task execution and objective accomplishment. However, it incorporates team adequacy as a significant job. In any case, the best test for team viability is a conflict that occurs from time to time within team individuals. In characterizing conflict, the strain happens among team individuals because of various views or discernments (Ancona et al., 2001). Regardless of contention being related to more noteworthy and successful work relationships, strife likewise forces a positive and negative effect on team Selection and friend survey under the obligation of the Organizing Committee work (De Dreu \& Weingart, 2003).

Along with these conflicts which occur within the organization workplace or a workgroup usually originate or cause due to contradiction of needs, norms, values, their level of interest and thinking as well as the perception of few people working together on that premises. Due to these different causes of conflicts, researchers divide and categorize conflicts into three main forms, which are relationship conflicts, task-oriented conflicts, and process-related conflicts (Brannick et al., 1997). Task conflict which occurs within the team members are usually caused a different point of view about a task procedure, disagreement on ideas shared by other team members, or sometimes a rarest case is about the task which is going to be done. Whereas relationship conflict mostly, includes personal problems which team members have may include tension, extra work pressure due to shortage of staff or sometimes due to absence of team member, frustration and personal differences which involves a single person attitude towards dealing other members, preferences likes and dislikes, personality and interpersonal style of handling human-resource-related issues and sometimes lack 
interpersonal interaction too (De Dreu \& Weingart, 2003). They were contented about the team and its effectiveness in work and different working aspects that, the effectiveness and efficiency of a team are mostly influenced by structure and criteria of the team on which it is established by higher management which includes the abilities of team members as well as team leader, characteristics on individuals as well as team, on the whole, roles, and responsibilities of team members, style and skills related to leadership and level of dependency, interdependency, and independence in taking decisions (Carson, Tesluk, \& Marrone, 2007).

This problem is pervasive in the information technology industry of Pakistan and it has a negative impact on the performance of the organizations. In the presence of conflicts, the performance of employees or team members seriously disturbs. Temporal leadership is nowadays used in organizations to deal with such sort of team conflicts. Leaders monitor the behaviour of the teams and try their best to focus teams on achieving their goals instead of doing conflicts. But there is a problem with temporal leadership too (Santos et al., 2016).

\subsection{Research Questions}

A summary of research questions is generated based on problems stated above, this study will help to figure out possible answers to the questions listed below:

- Research Question No 1: Does Task conflict lead to low project team performance?

- Research Question No 2: Does Relationship conflict lead to low project team performance?

- Research Question No 3: Does Process conflict leads to low project team performance?

- Research Question No 4: Does temporal leadership moderate the relationship between conflict and project team performance?

- Research Question No 5: Does temporal leadership moderate the relationship between task conflict and project team performance?

- Research Question No 6: Does temporal leadership moderate the relationship between process conflict and project team performance?

\section{Literature Review}

\subsection{Relationship between Team Conflict \& Project Team Performance}

Generally, team conflict occurs between members when there is some kind of real or perceived difference between their thoughts or way of working. The conflict within a team is well being defined by (Au \& Marks, 2012) that "an awareness on the part of parties involved of discrepancies, incompatible wishes, or irreconcilable desires." Team conflict is generally divided into three types which include relationship conflict, task conflict and process conflict. These all types of conflicts combine and generate a team conflict which occasionally effects the performance of team (De Dreu \& Weingart, 2003).

All the studies which are done so far in team conflict most of scholars used the theory of attraction and social identity theory explain the team conflicts. In attraction theory it is proposed that people prefer to interact with such type of people with whom they have some kind of similarities rather than dissimilar people, while if we study social identity theory, it suggests us that people like to stay in circle of only those people who are similar to their social category (Kankanhalli, Tan, \& Wei, 2006). In the light of these theories, when such type of diversified people is grouped on single platform and have to work in a team then they cause negative effects on the performance of the team which reduces the success ratio of project (Au \& Marks, 2012).

The team conflicts are a major issue, that not supposed to be neglect, if organizations are not effectively managing the conflict in the workplace, they face a lot of issues and problems in terms of output and effectiveness, to effectively managing workplace conflicts. Leaders need 
to focus the reasons why the conflicts are high in their project group, what to do to reduce the conflicts among team members. The findings of the study demonstrate that it can only be resolve through motivation and appreciation, when employees feel that their work is appreciated and there no favouritism, they become more productive and help each other which reduce the team stress and conflict in team. Leaders can motivate and appreciate their employees through foreign trip, work off, team of the month award, team outing, fun gatherings and many more (Eisenhardt, 2004).

Conflicts management and team performance has close relationship. When team conflicts resolve organizational productivity and efficiency increases, which leads team achieve their goals oriented in time. The finding of the study concluded that Organizations must have to implement strategies to reduce employee conflicts ratio intended for superior project team performance in organization by suitable employee management in organization (Fullan, 2007).

The correlation among conflict and team performance is unenthusiastic, when team members involve in team conflicts, they become non-productive. They considered themselves first rather than focus on the project. They not discuss the project requirement and not work together furthermore they only value their work and not focusing on team work goal. The result of the research concluded that they work as individual and only committed with their project task and not considered other team members in their activities which result poor team performance (Kankanhalli et al., 2006).

Team members considered as an important factor, for the success of any project. However due to time pressure, team members become stressful which result higher team conflicts occurs in the group, therefore temporary leadership is the best way to arranges groups toward dealing with the time-management perspectives or to meet the deadline. Managing team conflicts is quite a complex situation, when team goes through with conflicts, in this situation leaders become frustrated and make their effort to solve the team conflicts. The finding of the study concluded that, team conflicts effect the overall performance of the team and not provide valuable outcome which result low efficiency therefore organizations considered team conflicts a serious issue and they manage it immediately (Hackman, 1993).

Team conflict management is considered the best strategy for superior project performance. Team conflicts can be resolve through many ways like rewards, appreciation, and supportive work environment because it decreases job stress and workload which lead higher project performance and employee motivation. The finding of the study concluded that team conflicts decrease the performances of team members and considered the major issue of organization (Kankanhalli et al., 2006)

Therefore, it is hypothesized that:

- H1: Relationship Conflict is negatively associated with project team performance.

- H2: Task Conflict is negatively associated with project team performance.

- H3: Process Conflict is negatively associated with project team performance

\subsection{Moderating role of Temporal Leadership between Team Conflict \& Project Team Performance}

If one examines team leadership, then it has been highlighted as a base characteristic in leadership that determine effectiveness in performance of team (Zaccaro et al., 2001). Studying the recent research presented by Hackman (1993), it is identified in study that the impact of subjective involvement of influence on dynamics leadership affects the performance of team either in positive or in negative way but it depends on the way of involvement of leadership. Moreover, Mohammed and Nadkarni (2011) explains in their study that whenever a temporal diversity is practiced in an organization it effects the performance of team under the light of team conflicts. 
In case there are some team conflicts occurred then Temporal leadership influence on team and show direct as well as indirect effects on performance on team but these effects may be overseen after some time. According to a proposed study of Halbesleben (2003), if a leader provides a clear schedule to perform the tasks assigned to team and deliver its members a proper time frame to follow and also set of reminders along with the list of milestones, then it will help to increase the performance of team and maximize productivity of team.

\subsection{Temporal Leadership to Handle Project Team Performance under Relationship Conflict}

Temporal leaders and direct the team members how to perform the task. They are the ones who have the characteristics to attract their team members by their important skills and abilities, self-assurance and technical capability, which directly influence the behaviour, actions of the team member. They set their vision, craft a direction a, dream or path which facilitate their followers highly motivated to achieve their goals and objective. The finding of the study concluded that temporal leaders providing a path and solve conflicts between team members, which crafts an apparent and persuasive vision intending to achieve the project target. They have an ability to guess the requirement of the surroundings, they know how to deal in intense situation, how to solve the conflicts and facilitate the team members to deal with critical situation which make them most admired leader in front of their team members (Taormina \& Gao, 2013).

According to the research, team conflicts specially relationship conflicts decrease the project performances, due to which team members do not meet the desirable outcome. Relationship conflicts can be resolve through effective strategy of temporal leader, because temporal leader provides the path to the team members and direct them about the way of executing the tasks. The temporal leader solves queries and conflicts furthermore providing reward and punishment and motivates his/ her team to accomplish the project goal and help them to solve their conflicts with other team members. The finding of the study concluded that relationship conflicts decrease the project performance efficiency (Wang et al., 2012).

According to the researches, temporal leadership and conflicts management has a close relationship, temporal leadership is playing a major role to improve, efficiency, productivity and performance of the team. The capacity of workers inside an association is to part colleague everywhere throughout the association relies upon the conditions of their job environment the supportive and calm environment give the phase of fulfilment, increment inspiration and efficiency of workers, which result superior team performance. Furthermore, effective project management strategy helps leaders to boost efficiency and quality in its project. The outcome of the research demonstrates that, a well-organized project management procedure empowers associations to keep up manageable development of the organization. Project managing ensures the existence of right direction, at the accurate place, to the correct individual, and at the right time. It facilitates leaders to obtain reliable outcome in less time period (Brannick et al., 1997).

Temporal orientation generally become the reason of task conflicts between team members, because of short period deadline and bulk work, the employees feel pressure and stress which influence on team negatively and show direct as well as indirect effects on the performance of team. The result of the research reveals that team cannot attain project target in the desire time period (Hackman, 1993).

Conflict management in the team is quite a complex task a leader carries meant to achieve the project goal. Conflict management and project team performance has a close relationship, conflicts management can be solved through various ways by avoid, defeat, cooperation, compliant, and collaborate with team members, it's an everyday problem and the genuine procedure of dealing with the entire organization by utilizing various strategies and the leader who deal with the task are called project supervisor. An enormous association with huge size 
of venture may partition the task into various job of undertaking supervisors. The finding of the study concluded that for higher venture execution, the leader should design their principles, approaches and hierarchical structure that give strengthening to their worker to work well and pioneers ought to have an arrangement to value their representatives for their accomplishment, its legitimately builds representative resolve which result prevalent worker execution. At the point when workers are motivated, they become increasingly gainful towards venture objectives (Karimi et al., 2007).

Relationship conflicts are a major issue any team faced. The impact of task conflicts has a negative impact on project performance and can affect organizations output, production and efficiency. It can be resolved by implementing effective strategies of temporal leadership. Temporal leaders have the characteristics to motivate their team members to achieve the desirable goal. Motivated employees are more committed with their project; they are always available and work for the benefit of the organization. The findings of the study demonstrate that, the employees who obtain motivation from their leaders have superior self-esteem, high confidence, and extra willingness and higher job satisfaction which results elevated project performance. Employees who undergo with the work place conflicts not perform efficiently and not give their full effort in their work, which outcome lower project performance (Zaccaro et al., 2001).

Due to everyday changes in organizational demands, it has become a crucial role for team leaders to engage in temporal leadership behaviours in order to coordinate team members' efforts, avoid task related conflicts and to ensure that the team performs well, The findings of the study demonstrate that temporal leadership deals with effective task conflict management, the leaders analyse the situation and solve the conflicts by engaging with the team members, they work in friendly manner, talk with their team members, do not considered any member special, do not favour any member and appreciate everyone for their good work, meant to increase productivity and efficiency, they personally involve in project management and make strategies to meet the project deadline and make project successful (Baer \& Oldham, 2006).

Worker execution is directly based on the capacity of the training. training encourages to make unrivalled result in the group of the project, organization spend a lot of the capital for the completion of the training intended for civilizing and increase employee's ability, skills, aptitude and superior organizational productivity. Training and the employee development are entirely connected with the project performance and productivity. Training is the technique which is anxious with organizational productivity aimed at the recital of employees in organization. Training focal point is to provide edification to increase employee's efficiency for their project task as well as development of set up employees for expected responsibility and errands. It has an optimistic and positive relation with organizational productivity, development and growth; it is a process of transfer information and acquaintance to employees. The on-the-job training in organization considered the important factor meant to increase innovation and creativity in workplace. it provides efficiency and trained customer representatives as customers representatives are the ones who directly interact with your customers and convince them to solve their queries and make good relations with them intended to make them loyal. The outcomes of the study demonstrate that, the project of on job training is worn to achieve positive attitudes of team members and improve project progress in a positive manner as well as help them how deal in a particular situation with more calm and relax attitude to reduce relationship conflicts. Organization makes different training set and prepare a budget selected experienced and qualifies employers to give proper training to project team meant to target the project goal efficiently (Baer \& Oldham, 2006). 
Temporal leaders play a vital role in retention and conflicts the executives. Organization administrators unlock temporal leadership programs in associations to give better methods for group execution and to keep up and extend worker abilities and increment efficiency. The effective organizations are executing a business system that empowers the interest of workers in the task, expected to accomplish the hierarchical objectives and target, the outcome exhibit that, temporal leadership, participate a fundamental role in maintenance and conflicts management (Halbesleben, Novicevic, Harvey, \& Buckley, 2003).

Hence under light of above discuss it is hypothesized that:

- H4: Temporal leadership positively moderates the relationship between Relationship conflict and project team performance.

\subsection{Temporal Leadership to Handle Project Team Performance under Task Conflict}

Organization use the strategy to unlocking the temporal leadership strategy intended to achieve the higher project team performance, Temporal leaders use different strategies to increase the project performances or to decrease the team conflicts, to achieve the target, they investing quality and reasonable energy with time individuals, take care of their issues and help them to adjust occupation and family coexistence, which result workers become productive and increasingly efficient to accomplish the task goal. The finding of the investigation inferred that, it is important to the leaders to fabricate a sociable and highquality working atmosphere, the superior job environment where fell save, no biasness, reasonable choices, fair, no sexual orientation separation, well-disposed and open condition, it can diminish work related pressure and lift the degree of leader's fulfilment, which lead higher project team performance (Halbesleben et al., 2003).

Work place conflicts are solitary the imperative and significant issue dispute facing organizations nowadays. To overcome this, organization using temporal leadership strategy meant for higher organization's accomplishment, Employee growth is considered the most momentous purpose of individual resource practice which escort superior employee enthusiasm 'elevated commitment' and involve organizational result optimistically by shaping employee mind-set, behaviours, and motivation level .The finding of the study concluded that employee development is imperative in ornamental employee motivation furthermore developing the workplace conflicts is a major issue and decreases the competency and capabilities of employees as well as the organization as an entire which result low organizational effectiveness and job satisfaction.

Temporal leadership is clear as "leader behaviours that help in structuring, organizing and running the pace of task achievement in a group" a leader only avails those type of behaviour which are task oriented and are associated with completion of any task rather than developing relationships with team and adopting relationship-oriented behaviour in style. Hence this type of leadership style involves scheduling the tasks in such a manner that team members have to complete the tasks in specific time constrain to meet given requirements. The finding of the study concluded that temporal leaders effect performance of team members sometime in positive manner or in negative manner which depends upon the implementation of style on team (Marks et al. 2001).

Unlocking the temporal leadership strategy is use for higher project team performance, temporal leaders can be defined as, it provides guidance of team members, how to carry out the project activities, what ought to be done, what esteems and norms you assume and expect, help them to tackle their issues, mastermind worker acknowledgment programs and give hands on preparing that straightforwardly prompts higher group execution. Transient administration and task group execution have a positive relationship. The finding of the study concluded that unlock temporal leadership is the key and important factor to make project performance efficient (Maruping et al., 2015) 
Hence under light of above discuss it is hypothesized that:

- H5: Temporal leadership positively moderates the relationship between task conflict and project team performance.

\subsection{Temporal leadership moderates the relationship between process conflict and project team performance}

To improve the performance of the team or to solve process conflict, organization needs to implement temporal leadership program for higher efficiency and productivity in the organization. Temporal leadership and superior team performance have positive relationship, because temporal leaders solve the conflicts, managing the resources, allocating and assigning the task according to the skills and abilities of the team members, which result superior outcome and elevated performance of the team member. The findings concluded that organization implement temporal leadership program for higher efficiency and performance productivity in the organization (Halbesleben et al., 2003).

According to the researcher, the peoples who are involved with process conflicts among their colleagues, have less job satisfaction, they not perform efficiently and always want to switch the job and not achieve their job objectivities in time, which directly influencing the team performance. Superior team performance can only be achieved, when employees are engaged with their job. Employee engagement is a necessary part of good team performance. When employees are allowed to feel free of whatever they want to do, their productivity rises, they become so creative and productive, which result higher team performance and productivity in the organization. The findings of the research concluded that, temporal leadership leads career development opportunities for employees, temporal leaders provide complete expertise how to carry out the project and use advance technology which directly increase the career growth of the employees that leads high turnover rate in organization. Thus, temporal leadership has a negative relationship with the organization turnover rate (Bluedorn, 2002).

Critical assistance is being provided by temporal leaders assist, which helps to achieve the goals, as well as facilitate to come up with the innovative superior idea, they work as an analyst and always attract their team members with their enormous sense of humour with assisting them to construct project recital more efficient and successful. They are always willing to take a risk and encourage modification. They solve the problem efficiently, to complete the task requirement, or set up new different projects which create uniqueness in their work and make them successful leader, they always follow schedule and focus on short term project goal and only committed with the project rather than focus on any other subjective behaviour of team members for long term organizational benefit, the findings of the study concluded that temporal leaders positively help in conflicts management (Hackman,1993).

In today's world the company's essential need to look through the project task the leaders sets and aside their cash from over streaming as well as dealing with the entire project as per the given exhibition needs. It is the imperative and most significant method for the association to become familiar with the best strategies of project management since it might help or assist the association to find the specific goal. The outcomes demonstrate that, most of the organizations have a $70 \%$ of the task crash rate. $28 \%$ of the organizations are utilizing just explicit on performance requirements. Just 3\% of the organizations are completing the project successfully in the desire time period with no error (Hackman,1993).

The implementation of the temporal leadership can build a positive transformational for the performances of project team members and can affect on organizational change. It is a need of every critical project. The process temporal leadership impacts the progress decidedly, however if any progression is missed by the leader, at that point there would be a negative effect. If we think about a situation, the leader is actualizing project activities change and 
furthermore directions his team to follow. The leader has right to change or adjust the methodologies, approaches, activities and different administrations for the advancement and improvement of the exhibitions. The leader design the genuine need of objective, and decide how the team members will execute any changes, along these lines, the entire technique of leader ought to be plan as per the circumstance to get desire outcome on the project progress. The finding reveals that, temporal leadership is aimed towards bringing the project performances on the right direction, intended to achieve the project team goal. A clear vision and futurist approach of challenging the current situation of quo which generally need a person to perform the operation of determination of an individual performance towards the goal achievement in the presence of assumptions (Anderson \& Sun, 2017)

An association can achieve its blasting potential just by creation use of all the budgetary, corporal, and capital intended to increase the performance of employees, since when workers are happy with their job, they straightforwardly dedicated with their association and make best attempt to achieve their project objective proficiently. A worker's competency level isn't solidly associated with his ability and capabilities. The outcomes revels that, to get the fundamental result, a worker needs to have an awesome job security. Such parity can accompany to an increase in profitability and proficiency, sub-par operational expenses, just as a general advancement in adequacy, that can be achieve simply through job satisfaction (Kankanhalli et al.,2006).

On the job training Considered the best approach intended to increase organizational performance and assist to craft elevated result in project performance, if on the job training is better carry out in organization, project group efficiency also rise up, as when workers are skilled, they become more efficient and skilful and perform more efficiently furthermore on the job training also increases career growth which result team members become motivated The aptitude and effectiveness of employees can be worn in their own benefit, because of their career promotions, through which they become highly committed and devoted with the project and give their best intended to achieve the target easily . The findings reveals that, on the job training involves team to practice practically in a job and learn through the job activities it increases job satisfaction, team goodness and molarities, elevate the capability and efficiency, it's a method to trained project members how to exertion, providing knowledge how to work and how to perform in a definite mode, it's a technique to training team members to advance their expertise and aptitude to increase higher team performance (Anderson \& Sun, 2017)

The temporal leadership is the business strategy to increases project team performance, the organization use this strategy when company face tough time. This strategy was planned particularly for the up and down circumstances. The temporal leadership distinguishes the main variables what to require the change, and what step need to and settling on a few choices of progress as per the circumstance. The grouping of worldly authority is having a few stages and these are telling the heading, direct the project team members by legitimate instructing, directing, supporting, assignment to individuals and have consider the improvement level rather than focusing on the other long-term benefit (Eisenhardt, 2004). The temporal leadership can be applied in the context of organization, when organization facing issues to achieve the project goal, it defining and describing its main and core functions to the project team. The development methodology of temporal leadership includes two levels i.e., competence and commitment. The findings reveal that, the temporal leadership is relevant as the administration style ought to be assessed for efficiency. It is a significant approach to keep the business progress advance and stay profitable. However, if the method of leadership association decide is not relevant with group members, then the approach ought to be changed (Anderson \& Sun, 2017). 
The effectiveness of temporal leadership models and theories play a vital role in increasing the project team performance. Through these speculations the leaders have an indication of correspondence with the group members for achievement of project objectives. The leaders learn numerous aptitudes to keep up the undertaking progress on focus by advancement the activities and work quality of the team members under basic conditions. The style of initiative that is received by the leaders ought to be applied and help to support the psychological assessment of team members A qualifies leaders moves toward a practical method for creating strategies that is dealt with by the group members (Harrison \& Klein, 2007).

Temporal leaders can be characterizing as they set their vision, create a heading a, fantasy or way which encourage their colleagues profoundly energetic to accomplish their desire and target. This sort of leaders serves to giving a huge guidance which create a clear and powerful vision with intend to improve productivity and presentation. They know the matchless quality of verbal language and endeavour it proficiently to state prevalent prospects for the crew. They contain the matchless quality to figure the necessity of the environment, they realize how to unravel the group clashes, how to adapt up the conditions and help their devotees to manage circumstance which make them most respected pioneer before their colleagues. These leaders guide team members vary calmly by strong convincing power they share their strategies and tactics which makes the admirer sense as they participate in an enormously significant task, they consider every team member's decision important which result they induce easily and make more effective decisions, the findings reveal that, leaders help to providing an enormous and persuasive vision with the aim to improve project efficiency and recital (Maruping et al., 2015).

Temporal leadership increases the efficiency of protection rehearses and can prompt more significant levels of task achievement and manageability. The outcome revels that, Leadership in the association is a substantial part to influencing worker to achieve the project goal. Forefronts and group leaders keep in touch with staff performing routine assignments. The best leaders are probably going to get representative reliability, eventually prompting staff to remain inside the association by their great driving style. Anyway, transient Leadership can likewise build representative turnover because of high career growth (Guinan, Cooprider, \& Faraj,1998)

Temporal leaders are the ones who contain the attributes to pull in colleagues through their persuasive aptitudes and capacities, confidence and specialized ability, which impact the behaviour of a team member, activities and passionate difference in their colleagues. The use of verbal communication is being used by and preferred by temporal leaders instead of focusing on non-verbal communication. The leaders are seen as a moving icon who containing mysterious force, and appeal character; they are exceptionally vigorous as far as to pull in supporters easily. Hence the research findings concludes that temporal leaders roll out positive improvement in the presentation of group by inspiring workers through recognizing their potential abilities and persuade them to accomplish the venture objective and goal with proficient execution (Karimi, Somers, \& Bhattacharjee, 2007).

Hence under light of above discuss it is hypothesized that:

- H6: Temporal leadership positively moderates the relationship between process conflict and project team performance.

\section{Findings and Results}

After the completion of data collection with the help of survey questionnaire, next step is to analyse that information. With the help of this it is easy to check the proposed hypothesis of the research model. This analysis can lead towards discussion and as result this can lead towards suggestions in various fields. 
The goal of this section is to appear and clarify how information is investigated and what the outcomes behind that examination. There are different tools for the composition of initial data file and data screening of primary data such as checking missing attributes, normality, and multivariate outliers and alongside different descriptive data was SPSS 20.

There are multiple segments involved in this section of study. Foremost segment is the descriptive discussion about procedure of preliminary investigation of data. In the second section there will description of characteristics of demographics along with it there will be detailed description of the scales. Last segment contains the detailed discussion and results obtain from Structure Equation model (SEM). Following is the detailed discussion of each part

\subsection{Preliminary Data Screening}

Data in rough or crude form needs progression to change into useful form, because of different respondents and errors in the data. Tabulation analysis include misplaced values analysis, normality tests, various outlier screening, common procedure cross effect are conducted to perform the initial tests. Detail of data screening is defined in the segment below

\subsection{Missing Value}

To avoid the anomalies and error free results in future, the first step of analysis is to use missing value analysis (Wakefield et al., 2008). Among 459 questionnaire data there were not observed any missing value. So, data was complete and there was no missing value in it. This is shown in the following table below.

\subsection{Data Normality}

Skewness and kurtosis are the two measures to examine the assumptions of normality. For the examination of data distribution Skewness is used while kurtosis is used for the investigation of amplitude distribution. The scope of -1 to +1 are the values of Skewness while on the other hand values of kurtosis are within the range of -4 to +4 to make distribution of data normal (Fullan, 2007). When the value of Skewness and Kurtosis is zero this means that data indicates perfectly normal distribution.

\subsection{Outlier Analysis}

The analysis used to refine the normality of the statistics is known as outlier analysis. The huge value of a variable is the outlier which misstates the statistics and when size of the sample is small its effect is obvious (Karimi et al., 2007). Method of Statistical analysis is mostly used to check the outliers. Well in the data there is no outlier found. In our data set of 459 , the value of kurtosis and skewness for complete were within the range of normal distribution of quasi. So, there is no need to delete any item.

\subsection{Demographics}

The citizenry was clothing and fashion industry consumers. Survey of seven-point moderate scale was adopted from the existing documents for the record collection.

In this research paper almost data of 300 people were collected according to which $52.0 \%$ of respondents where male and $48.0 \%$ of respondents were female (see Table 1). All the respondents are currently working in different IT companies of Pakistan. 
Table 1.

Gender of respondents

\begin{tabular}{ccccc}
\hline & Frequency & Percent & Valid Percent & Cumulative Percent \\
\hline Male & 156 & 52.0 & 52.0 & 52.0 \\
Female & 144 & 48.0 & 48.0 & 100.0 \\
Total & 300 & 100.0 & 100.0 & \\
\hline
\end{tabular}

Moreover, the data which were collected was categorized in four major age groups which were starting from 20 years and last group includes respondents who were above 51 years of age. But in current data there was only 9 respondent who were the ages of 51 years or above. The frequency of age groups could be examined from Table 2.

Table 2.

Age groups of respondents

\begin{tabular}{lcccc}
\hline & Frequency & Percent & Valid Percent & Cumulative Percent \\
\hline 20-30 Years & 126 & 42.0 & 42.0 & 42.0 \\
31-40 Years & 101 & 33.7 & 33.7 & 75.7 \\
41-50 Years & 67 & 22.3 & 22.3 & 98.0 \\
Above 50 Years & 6 & 2.0 & 2.0 & 100.0 \\
\hline Total & 300 & 100.0 & 100.0 & \\
\hline
\end{tabular}

All the respondents were from strong educational background therefor educational details of respondents were also being collected to determine the education of respondents. Minimum education was Intermediate and maximum was $\mathrm{PhD}$ but currently there was no $\mathrm{PhD}$ holder respondent who provided his/her opinion (Table 3).

Table 3.

Educational details of respondents

\begin{tabular}{lcccc}
\hline & Frequency & Percent & Valid Percent & Cumulative Percent \\
\hline Matric & 1 & 0.3 & 0.3 & 0.3 \\
Intermediate & 25 & 8.3 & 8.3 & 8.7 \\
Bachelor & 138 & 46.0 & 46.0 & 54.7 \\
Masters & 103 & 34.3 & 34.3 & 89.0 \\
MPhil & 53 & 11.0 & 11.0 & 100.0 \\
Total & 300 & 100.0 & 100.0 & \\
\hline
\end{tabular}

While collecting data it is necessary to have firm information about experience of your respondent especially when your respondents are from cooperate sector. To fulfil this need experience of respondents were also retrieved from them which were also categorized in four groups (Table 4).

Table 4.

Experience of respondents

\begin{tabular}{lcccc} 
& Frequency & Percent & Valid Percent & Cumulative Percent \\
\hline Less than 1 Year & 51 & 17.0 & 17.0 & 17.0 \\
1-3 Years & 97 & 32.3 & 32.3 & 49.3 \\
3-6 Years & 82 & 27.3 & 27.3 & 76.7 \\
Above 6 Years & 70 & 23.3 & 23.3 & 100.0 \\
Total & 300 & 100.00 & 100.00 & \\
\hline
\end{tabular}

\subsection{Reliability analysis}

According to Baer \& Oldham (2006), reliability is defined as how much consistent the measure of concept is. This research has used an internal reliability as it has multiple measures with different constructs. The most important and useful method to measure internal reliability is Cronbach's alpha (Harrison \& Klein, 2007). If the value of Cronbach 
alpha falls in the range of 0.70-0.90 it means it will be high level reliability, if it falls in the range of $0.50-0.70$ it means it will be medium level and if its below than 0.50 then its lowlevel reliability (Harrison \& Klein, 2007). The Cronbach's alpha figure for all the variable is shown in Table 5.

The questionnaire which was presented in front of respondents to give their opinion was well tested for validity of questionnaire as well as reliability of questionnaire. The data which was attained from respondents was on Likert scale of five points.

Table 5.

Reliability analysis

\begin{tabular}{lcc}
\hline Variable Name & Mean & Cronbach's Alpha \\
\hline TTL & 3.3381 & 0.533 \\
PTP & 3.6458 & 0.469 \\
TC & 2.3658 & 0.629 \\
PC & 2.6978 & 0.604 \\
RC & 3.0392 & 0.524 \\
\hline
\end{tabular}

The alpha reliability of the scales is 0.533 for Team Temporal Leadership scale ( 7 items), 0.469 for Project team performance (4 items), 0.629 for Task conflict scale (4 items), 0.604 for Process conflict ( 3 items) and 0.524 for Relationship conflict (4 items) and a combine Cronbach's Alpha value of 0.615 for all the 5 variables (Table 6). As all the values of alpha are above 0.5 which is conventional standard, hence it's providing the evidence of validity of these measures.

Table 6.

combine Cronbach's Alpha

\begin{tabular}{cc}
\hline Cronbach's Alpha & N of Items \\
\hline .615 & 5 \\
\hline
\end{tabular}

\subsection{Correlation \& regression analysis}

3.4.1. Correlation Analysis

The Correlation Analysis in below Table 7 discloses the direction of relationship (either positive or negative) among variables. In this study, correlation analysis shows that all variables are correlated, mostly positive correlated as prescribed in the hypothesis. It depicts that TTL, PTP, TC, PC and RC are positively associated with each other.

Table 7.

Correlation Analysis

\begin{tabular}{lccccc}
\hline & $\mathbf{1}$ & $\mathbf{2}$ & $\mathbf{3}$ & $\mathbf{4}$ & $\mathbf{5}$ \\
\hline 1. $T C$ & 1 & & & & \\
2. $P C$ & $.426^{* *}$ & 1 & & \\
3. $R C$ & $.370^{* *}$ & $.202^{* *}$ & 1 & 1 & \\
4. $P T P$ & $-.283^{* *}$ & $-.473^{* *}$ & $-.285^{* *}$ & $.344^{* *}$ & 1 \\
5. TTL & $-.327^{* *}$ & $-.476^{* *}$ & $-.142^{*}$ &
\end{tabular}

\subsubsection{Regression analysis for determinants of Performance}

The Table 8 represents significant positive relationship of Task conflict and process conflict to experience with Project Team Performance whereas; Relationship Conflict is negatively associated with Project Team Performance. Firstly, the influence of demographic variables i.e., gender, age, qualification and experience are controlled and then regression analysis between concerned variables is performed. Furthermore, the value of R2 $=.205$ and $\mathrm{F}=$ 
34.45 , which depicts that the impact of other variables on project team performance is $65.5 \%$ with appropriate model fitness.

Table 8.

Regression analysis for determinants of Performance

\begin{tabular}{lccc}
\hline \multicolumn{1}{c}{ Predictors } & \multicolumn{1}{c}{ Performance } & $\mathbf{R}^{2}$ \\
\cline { 2 - 4 } Step 1 & & $\mathbf{R}^{2}$ & \\
Control Variables & & & \\
Step 2 & & .010 & \\
TC & -0.028 & & \\
PC & $-0.355^{* * *}$ & & .255 \\
RC & $-0.183^{* * *}$ & & \\
PTP & $0.515^{* * *}$ & .265 & \\
\hline$* p<.05, * * p<.01, * * * p<.001$ & & &
\end{tabular}

Although the correlation and regression statistics are significant but the small values indicates a none to minor negligible effect. The reason behind their small values are less data used for analysis purposes which is mentioned in limitation section of this study. As analysis was made on IT sector and multiple companies were involved in data collection process there for most of the companies were small scale companies with under 50 persons as workforce. Another reason was the consent shown by companies to collect data from their companies. Thats the reason if data is gathered from any larger industry, it will change the results and clearer image will be shown here.

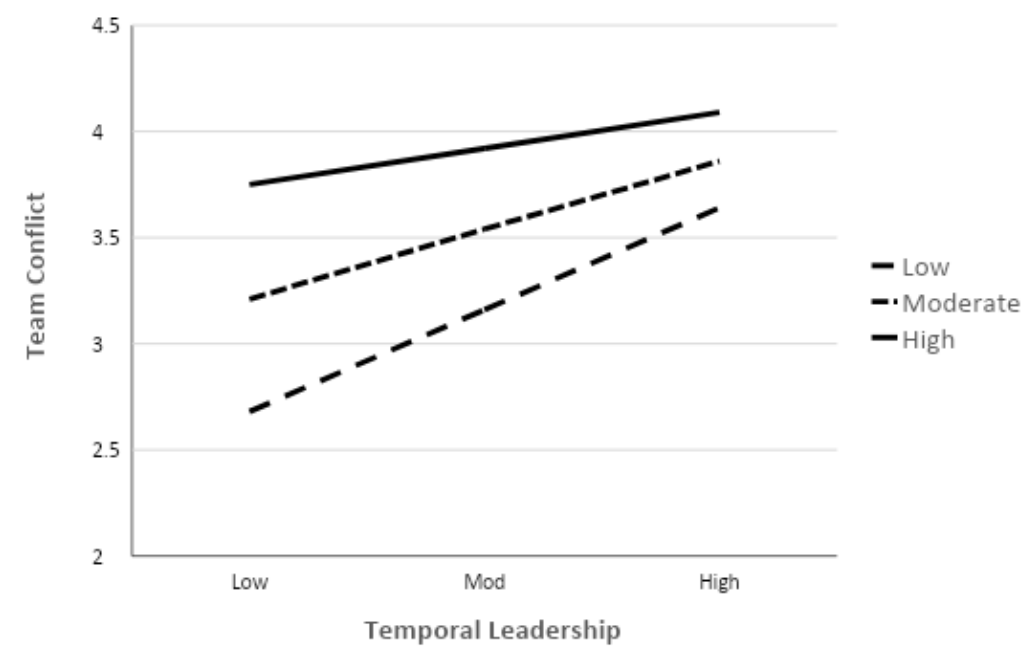

Figure 1. TL increases PTP in presence of TC

\subsection{Moderation Analysis}

In statistics and analysis of regression, moderation takes place when two variables are dependent on the third variable. This third variable is a moderator variable. The main purpose of this variable is to give direction and strengthen the consumer purchase attitude. In this paper the moderator is team temporal leader and conflicts are the independent variables which are negatively affecting the project team performance.

The main purpose of performing the moderation analysis is to identify the overall effect of the variable which is helping to over watch the relationship of independent and dependent variables. In this research work, the moderation analysis was being performed with the help of latent variable interaction. 
As shown in Table 8, the $t$ value is negative and both the values of Task conflict and Team temporal leader is significant. This means that task conflict could be controlled with the help of team temporal leader but it has a negative impact on project team performance. The interaction term between team temporal leadership and task conflict is also significant. This shows that in the presence of temporal leadership, task conflict which is affecting project team performance could be controlled in positive manner. Studies have shown that temporal leadership always help to moderate the effect of conflicts occurring in a team which directly or indirectly effect the performance of team.

Table 8.

Moderation Analysis

\begin{tabular}{lccccc}
\hline Model & \multicolumn{2}{c}{$\begin{array}{c}\text { Unstandardized } \\
\text { Coefficients }\end{array}$} & $\begin{array}{c}\text { Standardized } \\
\text { Coefficients }\end{array}$ & t & Sig. \\
\hline (Constants) & B & Std. Error & Beta & & \\
TC & 2.804 & 0.479 & & 5.856 & 0.000 \\
TTL & 0.144 & 0.180 & 0.159 & 0.803 & 0.001 \\
TTL x TC & 0.370 & 0.121 & 0.656 & 3.065 & 0.002 \\
\hline
\end{tabular}

a.

b. Dependent Variable: Mean PTP

In the Table 9, the value of $t$ is negative and but the Process conflict is not significant whereas team temporal leadership are significant. This shows that the process conflict has very less chances to be controlled under temporal leadership. The interaction term between team temporal leadership and process conflict is also not significant. This shows that in the presence of temporal leadership, process conflict which is affecting project team performance have very less chances to be controlled in positive manner. The moderating effect of temporal leadership helps to maintain the performance of project team while if there is a chance, process conflict occurs. With the help of team temporal leadership, process conflicts may be handled in such a way that project team performance is not disturbed.

Table 9.

Moderation Analysis

\begin{tabular}{lccccc}
\hline Model & Unstandardized Coefficients & $\begin{array}{c}\text { Standardized } \\
\text { Coefficients }\end{array}$ & t & Sig. \\
\hline & B & Std. Error & Beta & & \\
(Constants) & 3.903 & 0.432 & & -045 & 0.000 \\
PC & -0.158 & 0.146 & -0.187 & -1.079 & 0.282 \\
TTL & 0.233 & 0.119 & 0.414 & 1.965 & 0.050 \\
TTL x PC & -0.060 & 0.046 & -0.256 & -1.299 & 0.195 \\
\hline
\end{tabular}

a. Dependent Variable: Mean PTP

If the table 10 is examined and value of $t$ is closely checked it is clearly figured out that the variables Relationship conflict is not significant whereas temporal leadership are significant. This shows that relationship conflict in the presence of temporal leadership have very less chances to be controlled or may not be controlled. The interaction term between team temporal leadership and relationship conflict is also not significant. The non-significance of interaction term between team temporal leadership and relationship conflict shows that team temporal leadership have very less or no moderation effect on the association of relationship conflict and project team performance. Whereas the moderating effect of temporal leadership may not properly help to maintain the performance of project team while if there is a chance of occurrence of relationship conflict. 
Table 10.

Moderation Analysis

\begin{tabular}{lccccc}
\hline Model & \multicolumn{1}{c}{ Unstandardized Coefficients } & $\begin{array}{c}\text { Standardized } \\
\text { Coefficients }\end{array}$ & t & Sig. \\
\hline & B & Std. Error & Beta & & \\
(Constants) & 3.288 & 0.587 & & -601 & 0.000 \\
RC & -0.062 & 0.189 & -0.062 & -0.326 & 0.744 \\
TTL & 0.326 & 0.162 & 0.579 & 2.016 & 0.045 \\
TTL x RC & -0.052 & 0.054 & -0.305 & -0.958 & 0.339 \\
\hline
\end{tabular}

a. Dependent Variable: Mean PTP

\subsection{Hypothesis Summary}

Table 11 shows the acceptance and the rejection of the proposed hypothesis in this study. After performing different tests and analysis practices on the sample data collected with the help of questions adopted from different research works, the results of those tests and analysis practices shows significance. This significance shows that all the hypothesis are accepted and this research model is significant enough to implement.

Table 11.

Hypothesis Summary

\begin{tabular}{llc}
\hline No & \multicolumn{1}{c}{ Hypothesis } & Accepted / Rejected \\
\hline H1 & Relationship Conflict is associated with project team performance. & Accepted \\
H2 & Relationship Conflict is associated with project team performance. \\
H3 & $\begin{array}{l}\text { Process Conflict is associated with project team performance } \\
\text { Temporal leadership moderates the relationship between Relationship conflict } \\
\text { and project team performance. }\end{array}$ & $\begin{array}{c}\text { Accepted } \\
\text { Accepted }\end{array}$ \\
H5 $\begin{array}{l}\text { Temporal leadership moderates the relationship between task conflict and } \\
\text { project team performance. }\end{array}$ & Accepted \\
H6 $\begin{array}{l}\text { Temporal leadership moderates the relationship between process conflict and } \\
\text { project team performance. }\end{array}$ & Rejected \\
\hline
\end{tabular}

\section{Conclusion}

This paper is an output of the thesis written in MS Project management final year. According to which the main purpose of this study was to find the relation between different types of conflicts occur within a team with project team performance under the moderating role of temporal leadership. This section is related to the discussion about the above mentioned relationship in a detailed form and provides the explanation of the results with the help of theory supporting the relationship. The theoretical and practical implementation of study along with this the limitation and future scope of study is being highlighted in a proper manner. The main purpose of this study was to test the impact of team conflicts which include task conflicts, relationship conflicts and process conflicts on project team performance. Along with this the moderating role of temporal leadership was also tested in this study. Temporal leadership is currently in early stages of its development with respect to theoretical work done by different researchers as well as its implementation with in different grown and growing industries. Keeping these efforts in mind a solid evidence could be found that temporal leadership have a potential to influence on different industries and could increase a record number of its followers with the help of its positive results and strong employee leader bond creation capability.

If a discussion is made on results, it is clearly described that the relationship between project team performances in different types of team conflicts are significant. Also, the moderation hypothesis was accepted. With the help result the one can provide an evidence that project team performance decreases if there is any kind of conflict between / within a team which 
could be controlled and overcome with the help of temporal leadership (Harrison \& Klein, 2007).

Due to the factors of temporal leadership associated with positive outcome, it gains attention of researchers in last decade. It immediately controls the misunderstanding occurred within a project team with the help of its self-confidence. With the help of temporal leadership, a manager could easily organize, coordinate and distribute the task among its team and motivate them to give desired output results in a proper required manner (De Dreu \& Weingart, 2003). The hypothesis stated in this study are associated with the moderating role of temporal leadership between team conflicts and project team performance. Authors such as Morgeson concluded that "Temporal leadership which has its self-confidence and future related high-level view of their team, the way he performs his task and the Environment of his task accomplishment, has a very important and value able role for enabling his teams towards project success" (Hackman, 1990).

The relationship between, types of team conflicts and project team performance are significant and are negatively associated with each other, this shows that temporal leadership helps to increase the project team performance by controlling the conflicts occurring within the team. In the light of results, a synchronization is also found between the findings and social learning theory which states and supports that employee always learn with the help of environment they have in the surrounding. When an easy and relaxing environment is being provided to employees which include no conflicts and leg pulling this help employees to perform better in their tasks and give results beyond the expectations of management. Project team performance mainly focuses on the positive mindset of team members at their work places (Baer \& Oldham, 2006). According to the study of Perrin's Global workforce (2003), "the employee's capability and enthusiasm help the company to move towards success by providing mandatory efforts on the maintainable basis. work engagement is described and operationalized in its positive, satisfying, word related point of view that is represented by dedication, vigour, and absorption" (Anderson \& Sun, 2017).

In the nutshell, all the above discussions, analysis under the light of previous studies and theories concludes that when there is team conflict then the performance of team always reduces and manager could not increase the productivity of team under team conflict. The only way which is there for manager to overcome team conflict and to increase the performance of team to adopt temporal leadership and utilize its managerial resources. In Information Technology industry on which this was focused, team conflict mainly occurs as it's an industry of innovation and this always leave room of ideological conflict, decisional conflict, opinion-based conflict among team members. To utilize these conflicts in a positive way manager or team leader should utilize IT resources under the light of temporal leadership.

\subsection{Summary and Findings}

When some people are working in single environment and under one roof there is always possibility of disagreement between them. This disagreement if discussed in term of team conflict which include task conflict, relationship conflict and process conflict may sometime cause negative impact on team and sometimes cause positive impact on team. In this correlation matrix analysis (Table 6) it is clearly shown that team conflict has positive relation with project team performance. Here a conflict occurs; like Au \& Marks (2012) claims in their study that team conflict may affect team performance in a negative sense, in the light of their study it shows that all types of team conflicts must be negatively correlated with Project Team Performance. Whereas Kankanhalli, Tan, \& Wei (2006) in their study says that to some extant team conflict may put positive impact on Project Team Performance, in 
the light of their study it shows that Team Conflict should be positively correlated with Project Team Performance, which currently is reported in Table 6.

If $\mathrm{Au} \&$ Marks (2012) are considered as correct in this study then it also shows that TC under mediation of Temporal Leadership must have negative impact of Project Team Performance. Which thereafter if examines in Table 8, it clearly supports that Task Conflict (TC) must have negative impact on Project Team Performance under moderation of Temporal Leadership as it is being accepted that Task Conflict have negative impact on Project Team Performance. Therefore, it is clearly assumed from above results that Task Conflict has negative impact on Project Team Performance in moderation of Temporal Leadership.

Same the examination is being performed on Process conflict (PC) and relationship conflict (RC). Table 9 clearly supports under the light of above-mentioned theory that Process conflict is negatively impacting project team performance and under the moderation of temporal leadership, process conflict could be controlled due to its negative value mentioned in interaction term of PC and Temporal Leadership.

Similarly, Table 10 clearly supports under the light of above-mentioned theory that relationship conflict Relationship Conflict is negatively impacting project team performance PTP and under the moderation of temporal leadership TL, relationship conflict RC could be controlled due to its negative value mentioned in interaction term of RC and TL.

\subsection{Further research and Recommendations}

As IT is a fastest growing industry therefore there are many new openings for researchers on which they could bring useful studies. The topic of this research only highlights the managerial involvement of functions and their impacts on team performance, but not only management are involved, there are other factors too in Information Technology industry which influence on project team performance. These factors if could be discussed using some of above contributions could help to add new things in study. Also, team conflict's negative role is examined in current study. Positive role of team conflict could also be tested on this research model.

In the light of above study, it is recommended that the managers or project team leaders who are currently working in different IT companies of Pakistan, if adopt temporal leadership style while interacting with their team members and also utilize IT resources in such a way that it reduces team conflicts and help to increase the productivity of team. In Information Technology industry most of companies avoid to use IT functions in managing things, if those functions could be implemented in management side of IT, then it could help leaders a lot to achieve goals in faster and efficient way and also motivate teams to work in a positive way.

\subsection{Limitation of the study}

Although the effort was made to cover many aspects of industry but still the study is on smaller scale and may have some ambiguity in results. Collection of data was first hurdle which made it limited to attain more industrial reviews. This could be rectified if data is collected from multiple cities of Pakistan and again analysed with similar constitutions. As managerial side was supposed to discussed that's why other constrains which could affect performance of team were temporarily being neglected in study.

Another limitation of this study was its sector of study, where only companies dealing with Information technology related projects were studied and contacted which made this study a core study on information technology companies. To check the impact of study from another point of view future researchers could apply the research model on real estate companies and industries where multiple number of workers are working under one roof. Another best industry where this study could be applied is banking sector. In Pakistan banking sector have 
a strong chain of command and with large number of employees and proper hierarchy this study could perform better.

This study only examined the relationship of leader with employee and questions were asked from employees regarding their leadership, if leaders are questioned regarding their employees or both leader and employees are questioned together this study could give deeper and clearer image.

\section{References}

Ancona, D. G., Goodman, P. S., Lawrence, B. S., \& Tushman, M. L. (2001). Time: A New Research Lens. Academy Of Management Review, 26(4), 645-663.

Anderson, M. H., \& Sun, P. Y. (2017). Reviewing Leadership Styles: Overlaps and the Need for a New 'Full-Range'theory. International Journal of Management Reviews, 19(1), 7696.

Assaf, S., Hassanain, M. A., \& Mughal, H. (2014). Effectiveness of Project Teams and Their Impact on the Performance of Saudi Construction Projects. Research Journal of Applied Sciences, Engineering and Technology, 7(24), 5148-5156.

Au, Y., \& Marks, A. (2012). "Virtual Teams Are Literally and Metaphorically Invisible": Forging Identity in Culturally Diverse Virtual Teams. Employee Relations, 34(3), 271287.

Baer, M., \& Oldham, G. R. (2006). The Curvilinear Relation between Experienced Creative Time Pressure and Creativity: Moderating Effects of Openness to Experience and Support for Creativity. Journal of Applied Psychology, 91(4), 963.

Bluedorn, A. C. (2002). The Human Organization of Time: Temporal Realities and Experience. Stanford University Press.

Brannick, M. T., Salas, E., \& Prince, C. W. (Eds.). (1997). Team Performance Assessment and Measurement: Theory, Methods, and Applications. Psychology Press.

Carson, J. B., Tesluk, P. E., \& Marrone, J. A. (2007). Shared Leadership in Teams: An Investigation Of Antecedent Conditions And Performance. Academy Of Management Journal, 50(5), 1217-1234.

De Dreu, C. K., \& Weingart, L. R. (2003). Task versus Relationship Conflict, Team Member Satisfaction, and Team Effectiveness: A Meta-Analysis. Journal of Applied Psychology, 88(4), 741-749.

Eisenhardt, K. M. (2004). Five Issues Where Groups Meet Time. Time in Groups: Research on Managing Groups and Teams, 6, 267-283.

Fullan, M. (2007). Leading In a Culture of Change. John Wiley \& Sons.

Guinan, P. J., Cooprider, J. G., \& Faraj, S. (1998). Enabling Software Development Team Performance during Requirements Definition: A Behavioral Versus Technical Approach. Information Systems Research, 9(2), 101-125.

Hackman, J. R. (1990). Groups That Work and Those That Don't (No. E10 H123). JosseyBass.

Hackman, J. R. (1993). Teams, Leaders, and Organizations: New Directions for CrewOriented Frrght Training. 
Halbesleben, J. R., Novicevic, M. M., Harvey, M. G., \& Buckley, M. R. (2003). Awareness of Temporal Complexity in Leadership of Creativity and Innovation: A CompetencyBased Model. The Leadership Quarterly, 14(4-5), 433-454.

Harrison, D. A., \& Klein, K. J. (2007). What's The Difference? Diversity Constructs as Separation, Variety, or Disparity in Organizations. Academy Of Management Review, 32(4), 1199-1228.

Kankanhalli, A., Tan, B. C., \& Wei, K. K. (2006). Conflict and Performance in Global Virtual Teams. Journal of Management Information Systems, 23(3), 237-274.

Karimi, J., Somers, T. M., \& Bhattacherjee, A. (2007). The Role of Information Systems Resources in ERP Capability Building and Business Process Outcomes. Journal of Management Information Systems, 24(2), 221-260.

Kearney, E., \& Gebert, D. (2009). Managing Diversity and Enhancing Team Outcomes: The Promise of Transformational Leadership. Journal of Applied Psychology, 94(1), 77.

Marks, M. A., Mathieu, J. E., \& Zaccaro, S. J. (2001). A Temporally Based Framework and Taxonomy of Team Processes. Academy of Management Review, 26(3), 356-376.

Maruping, L. M., Venkatesh, V., Thatcher, S. M., \& Patel, P. C. (2015). Folding Under Pressure or Rising to The Occasion? Perceived Time Pressure and the Moderating Role of Team Temporal Leadership. Academy Of Management Journal, 58(5), 1313-1333.

McGrath, J. E. (1991). Time, Interaction, And Performance (TIP) A Theory of Groups. Small Group Research, 22(2), 147-174.

Mohammed, S., \& Nadkarni, S. (2011). Temporal Diversity and Team Performance: The Moderating Role of Team Temporal Leadership. Academy Of Management Journal, 54(3), 489-508.

Richard, O. C. (2000). Racial Diversity, Business Strategy, and Firm Performance: A Resource-Based View. Academy Of Management Journal, 43(2), 164-177.

Santos, C. M., Passos, A. M., Uitdewilligen, S., \& Nübold, A. (2016). Shared Temporal Cognitions as Substitute for Temporal Leadership: An Analysis of Their Effects on Temporal Conflict and Team Performance. The Leadership Quarterly, 27(4), 574-587.

Shaw, J. D., Zhu, J., Duffy, M. K., Scott, Shih, \& Susanto, E. (2011). A Contingency Model of Conflict and Team Effectiveness. Journal of Applied Psychology, 96(2), 391.

Taormina, R. J., \& Gao, J. H. (2013). Maslow and the Motivation Hierarchy: Measuring Satisfaction of the Needs. The American Journal of Psychology, 126(2), 155-177.

Wakefield, R. L., Leidner, D. E., \& Garrison, G. (2008). Research Note-A Model of Conflict, Leadership, and Performance in Virtual Teams. Information Systems Research, 19(4), 434-455.

Wang, N., Liang, H., Zhong, W., Xue, Y., \& Xiao, J. (2012). Resource Structuring or Capability Building? An Empirical Study of the Business Value of Information Technology. Journal of Management Information Systems, 29(2), 325-367.

Zaccaro, S. J., Rittman, A. L., \& Marks, M. A. (2001). Team Leadership. The Leadership Quarterly, 12(4), 451-483. 